\title{
Acute Thallium Poisoning: Series of Ten Cases
}

\author{
Fawzi Al Hammouri • Ghaleb Darwazeh • Anas Said • \\ Raed Abu Ghosh
}

Published online: 7 July 2011

(C) American College of Medical Toxicology 2011

\section{Introduction}

Thallium is a heavy metal used in cement, optical items, jewelry, electronic, and photographic industries. Thallium is colorless, water-soluble, and tasteless; therefore, it often passes unnoticed. It is extremely poisonous, and the lethal dose is estimated to be $10-15 \mathrm{mg} / \mathrm{kg}$ [1].

Thallium is excreted in breast milk and can cross the placental barrier [2]. Despite fetal complications ranging from severe toxicity and permanent deficit to normal development, the only consistent effect was increased risk of prematurity and low birth weight [3]. Acute thallium poisoning is usually due to ingestion of the salts, while chronic toxicity usually occurs by means of inhalation or skin absorption mostly secondary to chronic occupational exposure.

In 2008, two Iraqi families of 11 members developed symptoms after consuming variable amounts of cake that was prepared by a local bakery. The source and the way of thallium contamination of the cake were unknown. The family members were admitted to a local hospital and were suspected to have thallium poisoning based on their clinical presentation. The Poison Laboratory in Baghdad detected thallium in specimens taken from the patients and the contaminated cake.

This article was not presented at meetings or in abstract form.

F. Al Hammouri $(\bowtie)$

Department of Pediatrics, Specialty Hospital,

Box 930186, Amman 11193, Jordan

e-mail: fhammouri@gmail.com

G. Darwazeh · A. Said • R. A. Ghosh

Department of Medicine, Specialty Hospital,

Amman, Jordan
The patients were transferred to the Specialty Hospital in Amman, Jordan once the diagnosis was established because the antidote was not available in Iraq. The duration between poisoning and arrival to the specialty hospital in Jordan was 5-7 days.

One patient died in Iraq before being referred to our hospital, and therefore, was not included in the study.

The purpose of this series is to report the signs, symptoms, and laboratory abnormalities caused by thallium toxicity, and to describe the clinical course, management, and the outcome of the illness. The hospital's ethical committee approves reporting this case series, and the consents were collected from the patients and their guardians.

\section{Results}

The ten cases were members of two families. Four cases (father, mother, and two children) occurred in family 1 and six cases (father, mother, and four children) occurred in family 2. Table 1 shows the descriptive statistics of the cases, the initial symptoms, the interval between ingestion of the contaminated cake to symptom appearance and the blood/urine thallium concentration upon admission and 2 weeks after. The median interval from ingestion of the cake to symptoms appearance was $8 \mathrm{~h}$.

Nine cases ingested contaminated cake while one case was breastfed from a mother who ingested contaminated cake.

We were unable to have the initial thallium laboratory results of the patients from the hospital in Iraq. Thallium blood and urinary levels of the patients collected at admission (5-7 days after poisoning) and 2 weeks after are the only results available and are detailed in Table 1. 
Table 1 Descriptive statistics of the cases, initial symptoms, interval from thallium ingestion to symptoms appearance and blood and urine thallium concentration at admission and 2 weeks follow up

\begin{tabular}{|c|c|c|c|c|c|c|c|c|}
\hline Case no & Gender & $\begin{array}{l}\text { Age } \\
\text { (years) }\end{array}$ & First symptom & $\begin{array}{l}\text { Interval from } \\
\text { ingestion to } \\
\text { symptom } \\
\text { appearance (hours) }\end{array}$ & $\begin{array}{l}\text { Blood thallium } \\
\text { concentration } \\
\text { (mcg/L) at } \\
\text { admission }\end{array}$ & $\begin{array}{l}\text { Blood thallium } \\
\text { concentration } \\
(\mathrm{mcg} / \mathrm{L}) 2 \text { weeks } \\
\text { after treatment }\end{array}$ & $\begin{array}{l}\text { Urine thallium } \\
\text { concentration } \\
(\mathrm{mcg} / \mathrm{L}) \text { at } \\
\text { admission }\end{array}$ & $\begin{array}{l}\text { Urine thallium } \\
\text { concentration } \\
(\mathrm{mcg} / \mathrm{L}) 2 \text { weeks } \\
\text { after treatment }\end{array}$ \\
\hline 1 & Female & 30 & $\begin{array}{l}\text { Lower limb pain } \\
\text { and weakness }\end{array}$ & 6 & 380.00 & 46 & 1802.00 & 150 \\
\hline 2 & Male & 2 & Vomiting & 24 & 1700.00 & Deceased & 2552.00 & Deceased \\
\hline 3 & Female & 5 & Vomiting & 72 & 289.00 & 5 & 1959.00 & 44 \\
\hline 4 & Male & 14 & $\begin{array}{l}\text { Lower limb pain } \\
\text { and weakness }\end{array}$ & 10 & 205.00 & 11 & 2312.00 & 79 \\
\hline 5 & Male & 7 & $\begin{array}{l}\text { Lower limb pain } \\
\text { and weakness }\end{array}$ & 5 & 434.00 & 20 & 2909.00 & 131 \\
\hline 6 & Male & 39 & $\begin{array}{l}\text { Lower limb pain } \\
\text { and weakness }\end{array}$ & 6 & 1406.00 & 730 & 2462.00 & - \\
\hline 7 & Female & 27 & $\begin{array}{l}\text { Lower limb pain } \\
\text { and weakness }\end{array}$ & 6 & 208.00 & 10 & 1495.00 & 107 \\
\hline 8 & Female & 18 & $\begin{array}{l}\text { Lower limb pain } \\
\text { and weakness }\end{array}$ & 48 & 53.00 & 53 & 452.00 & 27 \\
\hline 9 & Male & 7 & Vomiting & 72 & 358.00 & 11 & 2312.00 & 149 \\
\hline 10 & Male & 42 & $\begin{array}{l}\text { Lower limb pain } \\
\text { and weakness }\end{array}$ & 4 & 58.00 & 6 & 781.00 & 42 \\
\hline
\end{tabular}

\section{Symptoms and Signs}

The gastroenterological, neurological, and visual symptoms of the cases present at time of admission are shown in Table 2.

Other reported symptoms include skin rash, chest pain related to deep inspiration (pleuritic chest pain), and chest tightness.

\section{Physical Examination}

Signs of thallium poisoning detected at time of admission or during hospital stay are shown in Table 3.

\section{Laboratory and Imaging Results}

At the time of admission, blood indices were collected and anemia was detected in one case, elevated white blood cell count in four cases, thrombocytopenia in one case, hypokalemia in six cases, elevated creatinine in three cases, hypermagnesemia in three cases, hypomagnesaemia in one case, elevated LDH in six cases, elevated AST in seven cases, elevated ALT in four cases, direct hyperbilirubinemia in two cases, and elevated gamma GT in four cases; otherwise, the remaining results were within the normal range. Previous laboratory investigations performed in Iraq were not available.

Blood and urine samples were sent for quantitative thallium levels upon admission. Thallium was detected in all cases; the median blood thallium level was $323.5 \mu \mathrm{g} / \mathrm{L}$ (range, $53-1700 \mu \mathrm{g} / \mathrm{L}$ ). The median urine thallium level of nine cases was $1,959 \mu \mathrm{g} / \mathrm{L}$ (range, 452-2,909 $\mu \mathrm{g} / \mathrm{L}$ ). Thallium was also detected in a sample of the contaminated cake. The icing contained $5.6 \%$ thallium while the pastry contained $1.1 \%$ thallium.

During the hospital stay, serial investigations were performed and remarkable changes in the laboratory results were noticed (Table 4). Blood and urine samples of eight surviving cases were sent for thallium levels 2 weeks after initiating therapy; the median blood thallium concentration was $10.5 \mu \mathrm{g} / \mathrm{L}$ (range, 5-46 $\mu \mathrm{g} / \mathrm{L}$ ). The median urine thallium concentration was $79 \mu \mathrm{g} / \mathrm{L}$ (range, $27-150 \mu \mathrm{g} / \mathrm{L})$.

Three cases had abnormal CT scans; two cases developed marked cerebral edema and increased intracranial pressure, while one case developed progressive widening of the brain CSF spaces without cerebral edema.

\section{Clinical Course and Management}

All cases were managed initially by peritoneal dialysis in Baghdad before being transferred to Amman. Nine cases continued on hemodialysis until the antidote was available. The median number of dialysis sessions was four (range, one to nine sessions) each for $1.5-2 \mathrm{~h}$.

The antidote Prussian blue was given in the form of $0.5 \mathrm{~g}$ capsules. Children were given $250 \mathrm{mg} / \mathrm{kg} / \mathrm{day}$ divided into four equal doses. Adults received $3 \mathrm{~g}$ three to four times daily. 
Table 2 Symptoms of thallium poisoning at time of presentation
- developed the symptom; ‡ symptom could not be assessed

\begin{tabular}{|c|c|c|c|c|c|c|c|c|c|c|c|}
\hline \multirow[t]{2}{*}{ Symptoms } & \multicolumn{10}{|c|}{ Case } & \multirow[t]{2}{*}{$n$} \\
\hline & 1 & 2 & 3 & 4 & 5 & 6 & 7 & 8 & 9 & 10 & \\
\hline \multicolumn{12}{|l|}{ Gastroenterological } \\
\hline Abdominal pain & $\bullet$ & $\neq$ & $\bullet$ & $\bullet$ & $\bullet$ & $\bullet$ & $\bullet$ & $\bullet$ & $\bullet$ & & 8 \\
\hline Nausea/Vomiting & $\bullet$ & $\bullet$ & $\bullet$ & $\bullet$ & & $\bullet$ & $\bullet$ & $\bullet$ & $\bullet$ & & 8 \\
\hline Constipation & $\bullet$ & $\neq$ & $\bullet$ & $\bullet$ & $\bullet$ & $\bullet$ & $\bullet$ & $\bullet$ & $\bullet$ & & 8 \\
\hline Diarrhea & & & $\bullet$ & $\bullet$ & & & & & & & 2 \\
\hline \multicolumn{12}{|l|}{ Neurological } \\
\hline Lower limb pain & $\bullet$ & $\neq$ & $\neq$ & $\bullet$ & $\neq$ & $\bullet$ & $\bullet$ & $\bullet$ & $\bullet$ & $\bullet$ & 7 \\
\hline Ascending pain & $\bullet$ & $\neq$ & $\neq$ & $\bullet$ & $\neq$ & $\bullet$ & $\bullet$ & $\bullet$ & $\bullet$ & $\bullet$ & 7 \\
\hline Weakness & $\bullet$ & $\bullet$ & $\bullet$ & $\bullet$ & $\bullet$ & $\bullet$ & $\bullet$ & $\bullet$ & $\bullet$ & & 9 \\
\hline Balance loss & $\bullet$ & $\neq$ & $\bullet$ & $\bullet$ & $\bullet$ & & & & $\bullet$ & & 5 \\
\hline Tremor & $\bullet$ & $\neq$ & & $\bullet$ & $\bullet$ & & & & $\bullet$ & & 4 \\
\hline Involuntary movements & & $\neq$ & $\bullet$ & $\bullet$ & $\bullet$ & & & & $\bullet$ & & 4 \\
\hline Dysphagia & $\bullet$ & $\bullet$ & $\bullet$ & $\bullet$ & $\bullet$ & $\bullet$ & $\bullet$ & $\bullet$ & $\bullet$ & & 9 \\
\hline Difficult speech & $\bullet$ & $\neq$ & $\bullet$ & $\bullet$ & $\neq$ & & $\bullet$ & & $\bullet$ & & 5 \\
\hline Headache & $\bullet$ & $\neq$ & & $\bullet$ & $\neq$ & $\bullet$ & $\bullet$ & $\bullet$ & $\bullet$ & $\bullet$ & 7 \\
\hline Loss of consciousness & $\bullet$ & $\bullet$ & $\bullet$ & $\bullet$ & $\bullet$ & & & & & & 6 \\
\hline Seizures & & $\bullet$ & $\bullet$ & $\bullet$ & $\bullet$ & & & & $\bullet$ & & 5 \\
\hline Insomnia & $\bullet$ & $\neq$ & $\bullet$ & $\bullet$ & $\bullet$ & $\bullet$ & $\bullet$ & $\bullet$ & $\bullet$ & $\bullet$ & 9 \\
\hline Psychotic features & $\bullet$ & & $\neq$ & $\bullet$ & $\bullet$ & & $\bullet$ & & $\bullet$ & & 5 \\
\hline \multicolumn{12}{|l|}{ Visual } \\
\hline Double vision & $\bullet$ & $\neq$ & $\neq$ & $\bullet$ & $\neq$ & & & & & & 2 \\
\hline Abnormal visual acuity & & $\neq$ & $\neq$ & $\bullet$ & $\neq$ & & & & & & 1 \\
\hline \multicolumn{12}{|l|}{ Others } \\
\hline Skin rash & & & & $\bullet$ & $\bullet$ & & & $\bullet$ & $\bullet$ & & 4 \\
\hline Pleuritic chest pain & & $\neq$ & $\neq$ & $\bullet$ & $\neq$ & $\bullet$ & $\bullet$ & & & $\bullet$ & 4 \\
\hline Chest tightness & $\bullet$ & $\neq$ & $\bullet$ & $\bullet$ & $\neq$ & $\bullet$ & $\bullet$ & $\bullet$ & $\bullet$ & & 7 \\
\hline
\end{tabular}

The management of neuropathic pain involved the use of a combination of opiates, anticonvulsants and antidepressants. For the first few days, Pethidine and Tramadol were used for analgesia. All cases were given Gabapentin; children received $300 \mathrm{mg} /$ day, while adults were given $400 \mathrm{mg}$ twice daily. Two children received $200 \mathrm{mg}$ Carbamazepine divided into two equal doses. Amitriptyline was initiated at oral doses of $25 \mathrm{mg}$ for adults and $12.5 \mathrm{mg}$ for children at bed time. All cases were given lactulose for constipation, and B complex supplements. Pruritis secondary to eczematous rash was alleviated with antihistamines and calamine lotion. Patients who developed severe anemia and elevated INR received packed RBC and fresh frozen plasma, respectively. Electrolyte replacements were administered as needed.

Five cases were admitted to the intensive care unit (ICU) at some time during hospitalization. Three cases developed loss of consciousness, coma, and were subsequently mechanically ventilated. Two cases developed recurrent choking; one of which developed aspiration pneumonia, and was fed by means of a nasogastric tube until discharge. One female case was pregnant in the first trimester and her clinical course was complicated by severe urinary tract infection for which she had to receive antibiotics. The pregnancy was electively terminated due to the possible teratogenic effect of the antidote and the medication she received.

\section{Outcome}

Cases 2, 3, 5, 6, and 9 were admitted to the ICU. Three patients died while in the ICU; two children (cases 2 and 3 ) developed sudden cardio-respiratory arrest, while one adult (case 6) developed multi organ failure followed by cardiorespiratory arrest.

\section{Discussion}

The course of acute thallium poisoning is divided into three phases. The first phase represents the intravascular distribution that lasts approximately for the first $4 \mathrm{~h}$. Afterwards, 
Table 3 Signs of thallium poisoning detected at admission or during hospital stay
- Developed the sign, $\neq$ could not be assessed, $\downarrow$ decreased reflexes, $\leftrightarrow$ normal reflexes

\begin{tabular}{|c|c|c|c|c|c|c|c|c|c|c|c|}
\hline \multirow[t]{2}{*}{ Signs } & \multicolumn{10}{|c|}{ Case no. } & \multirow[t]{2}{*}{$n$} \\
\hline & 1 & 2 & 3 & 4 & 5 & 6 & 7 & 8 & 9 & 10 & \\
\hline \multicolumn{12}{|l|}{ Skin, hair, and nails } \\
\hline Alopecia & $\bullet$ & & $\bullet$ & $\bullet$ & $\bullet$ & & $\bullet$ & $\bullet$ & $\bullet$ & & 7 \\
\hline Loss of lateral third of eyebrows & $\bullet$ & & & $\bullet$ & & & $\bullet$ & & $\bullet$ & & 4 \\
\hline Acne & & & & & & & & $\bullet$ & & & 1 \\
\hline Hair discoloration & & & & & $\bullet$ & & $\bullet$ & $\bullet$ & $\bullet$ & & 4 \\
\hline Dry skin & & & $\bullet$ & & & & & & & & 1 \\
\hline Scaling of palms and soles & $\bullet$ & & $\bullet$ & $\bullet$ & $\bullet$ & $\bullet$ & $\bullet$ & & $\bullet$ & & 7 \\
\hline Mees lines & & & & $\bullet$ & & & & & & & 1 \\
\hline Eczematous lesions & & & & $\bullet$ & $\bullet$ & & & $\bullet$ & $\bullet$ & & 4 \\
\hline \multicolumn{12}{|l|}{ Gastroenterological } \\
\hline Glossitis & & & & & & & & $\bullet$ & & & 1 \\
\hline Stomatitis & & & $\bullet$ & & & & & & & & 1 \\
\hline Abdominal tenderness & $\bullet$ & $\neq$ & & $\bullet$ & $\bullet$ & $\bullet$ & $\bullet$ & & $\bullet$ & $\bullet$ & 7 \\
\hline Abdominal guarding & & & & & & $\bullet$ & $\bullet$ & & & & 2 \\
\hline Hyperactive bowel sounds & & & & & & & $\bullet$ & & & & 1 \\
\hline \multicolumn{12}{|l|}{ Neurological } \\
\hline Ptosis & & $\neq$ & $\neq$ & $\bullet$ & $\bullet$ & $\bullet$ & & & $\bullet$ & & 4 \\
\hline Abnormal neurological examination & $\bullet$ & $\bullet$ & $\bullet$ & $\bullet$ & $\bullet$ & $\bullet$ & $\bullet$ & & $\bullet$ & & 8 \\
\hline Abnormal power & $\bullet$ & $\bullet$ & $\bullet$ & $\bullet$ & $\bullet$ & $\bullet$ & $\bullet$ & & $\bullet$ & & 8 \\
\hline Muscle power & $3 / 5$ & $1 / 5$ & $\neq$ & $\neq$ & $\neq$ & $3 / 5$ & $4 / 5$ & $5 / 5$ & $\neq$ & $5 / 5$ & \\
\hline Impaired proprioception & & $\neq$ & $\neq$ & $\bullet$ & $\bullet$ & $\bullet$ & & & $\bullet$ & & 4 \\
\hline Impaired pin-prick sensation & & $\neq$ & $\neq$ & $\bullet$ & $\bullet$ & $\bullet$ & & & $\bullet$ & & 4 \\
\hline Impaired fine touch sensation & & $\neq$ & $\neq$ & $\bullet$ & $\bullet$ & $\bullet$ & & & $\bullet$ & & 4 \\
\hline Abnormal reflexes & $\bullet$ & $\bullet$ & $\bullet$ & $\bullet$ & $\bullet$ & $\bullet$ & & & $\bullet$ & & 7 \\
\hline Deep tendon reflexes & $\downarrow$ & $\downarrow$ & $\downarrow$ & $\downarrow$ & $\downarrow$ & $\downarrow$ & $\leftrightarrow$ & $\leftrightarrow$ & $\downarrow$ & $\leftrightarrow$ & \\
\hline
\end{tabular}

the thallium is distributed in the central nervous system and this second phase lasts for $48 \mathrm{~h}$. The third phase is the elimination phase mainly through the gastrointestinal and renal system which begins $24 \mathrm{~h}$ later [4].

The clinical manifestations of thallium poisoning depend on the dosage, body weight, individual susceptibility, and the onset of treatment.

Gastroenterological, neurological, and dermatological symptoms are the main symptoms of acute thallium poisoning [5-7]. This led to a long list of differential diagnosis from gastrointestinal, neurologic, psychiatric, dermatologic, and cardiac manifestations. The first symptoms are from the digestive tract; abdominal pain, nausea, diarrhea, perhaps vomiting with constipation. Shortly after, neurological symptoms appear; there is hypersensitivity to touch and pain, unusual phantom sensation as well as muscle weakness that often began in the sole of the feet and the big toe and slowly spread up to the rest of the body. Movement may also become clumsy. The pain hypersensitivity can be so extreme that the brush of a feather can cause intense pain. The victim may salivate excessively. There may be excessive thirst. Psychiatric disturbances such as delirium, restlessness, hallucinations, and delusions are common. There may be eye turn or crossed eyes. Color perception may be altered. Blindness due to optic neuritis is frequent. Convulsions are occasionally seen. Liver and kidney damage often occur. One week after ingestion, the hair starts to fall out and the outer part of the eyebrows is lost. Children tend to develop psychiatric disturbances more than adults while adults are more prone to develop weaknesses, hypersensitivity, and cardiac arrhythmias.

The details of clinical presentation of our case series are detailed in Tables 2 and 3. Gastroenterological symptoms developed in nine cases; mainly abdominal pain, nausea, and vomiting. Constipation most likely developed as a side effect of antidote therapy with Prussian blue [8]. Most of our cases developed neurological manifestations.

Peripheral neuropathy occurred in the form of burning and electrical shock-like pain, motor weakness, sensory abnormalities, hyperesthesia, and decreased deep tendon reflexes. This has shown to be due to axonopathy with secondary demyelination [9].

None of the cases had abnormal cranial nerve examination. Loss of balance was likely due to the impairment of 
Table 4 Abnormal laboratory results (blood and serum levels) detected during hospital stay

\begin{tabular}{|c|c|c|c|c|c|c|c|c|c|c|c|c|}
\hline & \multicolumn{10}{|c|}{ Case no. } & \multirow[t]{2}{*}{ Median } & \\
\hline & 1 & 2 & 3 & 4 & 5 & 6 & 7 & 8 & 9 & 10 & & \\
\hline Maximum hemoglobin drop $(\mathrm{g} / \mathrm{dL})$ & 4.00 & 3.20 & 6.70 & 4.50 & 2.10 & 6.00 & 4.90 & 3.20 & 2.60 & & 4.00 & \\
\hline Minimum platelet count/L & & 90.00 & 60.00 & & & 125.00 & & & & & 90.00 & \\
\hline Maximum platelet count/L & & & & 559.00 & 654.00 & 501.00 & & & & & 559.00 & \\
\hline Maximum INR & & 1.30 & & & 1.70 & 2.30 & & & & & 1.70 & \\
\hline Minimum sodium $(\mathrm{mmol} / \mathrm{L})$ & 132.00 & 128.00 & 130.00 & & 130.00 & & & & 132.00 & & 130.00 & \\
\hline Minimum potassium $(\mathrm{mmol} / \mathrm{L})$ & 3.20 & 2.90 & 2.40 & 3.30 & 3.20 & & 3.10 & 3.10 & 3.10 & 3.40 & 3.10 & \\
\hline Minimum magnesium (mmol/L) & & 1.30 & 1.00 & & & 1.80 & & & & & 1.30 & \\
\hline Maximum magnesium (mmol/L) & & & & 2.80 & 2.30 & 2.90 & & & 2.50 & & 2.65 & \\
\hline Maximum creatinine (mg/dL) & & 1.10 & 1.10 & & & 2.10 & & & & & 1.10 & \\
\hline Maximum LDH (IU/L) & 285.00 & 423.00 & 408.00 & 319.00 & 255.00 & 623.00 & & & & & 319.00 & \\
\hline Maximum ALT (IU/L) & 448.00 & & 63.00 & 56.00 & 93.00 & 658.00 & & & & & 270.50 & \\
\hline Maximum AST (IU/L) & 183.00 & 44.00 & 74.00 & 40.00 & & 517.00 & & & & 40.00 & 74.00 & \\
\hline Maximum direct bilirubin $(\mathrm{mg} / \mathrm{dL})$ & 1.50 & & & & & 1.30 & & & & & 1.50 & \\
\hline Maximum ALKP (IU/L) & 173.00 & & & & & 201.00 & & & & & 173.00 & \\
\hline Maximum GGT (IU/L) & 361.00 & & & & & 210.00 & & & & & 295.00 & \\
\hline Minimum albumin $(\mathrm{g} / \mathrm{dL})$ & & 3.20 & 3.60 & & & 2.60 & & & & & 3.20 & \\
\hline
\end{tabular}

proprioception sensation, as cerebellar signs were negative and nystagmus was absent in our patients. Weakness in verbal abilities reported by previous studies was evident in our cases [10]. Facial nerve paralysis reported was not seen in our cases [7]. Two patients developed double vision, while extraocular muscle movement was intact. Dermatological manifestations including the characteristic alopecia that occurs after the second week of poisoning, scaling of the palms and soles, Mees' lines (white transverse bands on the nails), acneform lesions, loss of the lateral third of eyebrows, hair discoloration and eczematous rash were seen in our patients. These manifestations are thought to occur due to secondary deficiency of riboflavin $[6,11]$. None of our cases developed palmar erythema.

Laboratory abnormalities detected in this series included normochromic normocytic anemia, thrombocytopenia, thrombocytosis, hyponatremia, hypokelemia, and hypoand hypermagnesemia. Hypokalemia is likely to be a side effect of Prussian blue administration [8]. Thallium is concentrated into certain cells because it binds to a specific site on a cell surface mineral transport protein that is normally used to uptake potassium in exchange for sodium causing hypokalemia mainly. This could explain hypokalemia in addition to vomiting and diarrhea; however, Prussian blue is also known to cause hypokalemia. Laboratory results suggestive of hepatic and renal damage were also evident in some of our cases (Table 4).

Early detection of cases of thallium poisoning and the initiation of management has shown to improve survival, reduce the duration of illness and minimize the extent of neurological damage [12]. Prussian blue, the antidote for thallium poisoning and hemodialysis are the cornerstones in acute thallium poisoning management. Hemodialysis has proved to be effective up to 3 weeks after intoxication [7]. Prussian blue acts by forming insoluble complexes with thallium ions in the gut and thereby disrupting the enteric circulation of thallium and enhancing fecal excretion. Common side effects of Prussian blue are hypokalemia and constipation; therefore, serum electrolytes should be closely monitored and laxatives should be considered [8].

According to the United States Food and Drug Administration, the use of Prussian blue in animal reproduction has shown an adverse effect on the fetus. On human fetuses, there are no reports in literature; however, one female patient in our series, who was pregnant in the first trimester, elected to terminate her pregnancy due to the possible teratogenic effect of the antidote.

Other aspects of management in cases of acute thallium poisoning include neuropathic pain management, anticipation, and correction of electrolyte abnormalities and potassium supplements to replace deficit and possibly enhance thallium clearance from body compartments [13]. Normally, thallium levels should not be identified in urine or blood; however, blood thallium levels are often falsely normal (low) in poisoned people, urine collection in $24 \mathrm{~h}$ are somewhat more reliable but false normal is still common [14].

Supportive and symptomatic measures were offered to all our patients. NSAIDs are better avoided in cases of thallium poisoning as they may contribute to gastrointesti- 
nal upset, hepatotoxicity, and nephrotoxicity. Although children among our cases had lower blood thallium levels, they showed higher mortality. This may be attributed to their lower body weight, and hence, larger concentration of thallium in tissues in comparison to adults.

In conclusion, thallium poisoning should be considered in patients present with sudden onset of symmetrical lower limbs, neuropathy, and gastrointestinal symptoms. Thallium is excreted in breast milk and lactating cases should stop breast feeding until blood thallium levels return to normal. Early management with hemodialysis and Prussian blue improves survival and minimizes the extent of neurological damage. Other aspects of conservative management might have a role in improving survival and minimizing deficits.

Source of Funding None.

Conflict of Interest None.

\section{References}

1. Moore D, House I, Dixon A (1993) Thallium poisoning. Diagnosis may be elusive but alopecia is the clue. BMJ 306 (6891):1527-1529
2. Léonard A, Gerber GB (1997) Mutagenicity, carcinogenicity and teratogenicity of thallium compounds. Mutat Res Rev Mutat Res 387(1):47-53

3. Hoffman RS (2000) Thallium poisoning during pregnancy: a case report and comprehensive literature review. J Toxicol Clin Toxicol 38(7):767-775

4. Cavanagh JB (1991) What have we learnt from Graham Frederick Young? Reflections on the mechanism of thallium neurotoxicity. Neuropathol Appl Neurobiol 17(1):3-9

5. Mulkey JP, Oehme FW (1993) A review of thallium toxicity. Vet Hum Toxicol 35(5):445-453

6. Meggs WJ, Hoffman RS, Shih RD, Weisman RS, Goldfrank LR (1994) Thallium poisoning from maliciously contaminated food. J Toxicol Clin Toxicol 32(6):723-730

7. Misra UK, Kalita J, Yadev RK, Ranjan P (2003) Thallium poisoning: emphasis on early diagnosis and response to haemodialysis. Postgrad Med J 79(928):103-105

8. Hoffman RS (2003) Thallium toxicity and the role of Prussian blue in therapy. Toxicol Rev 22(1):29-40

9. Dumitru D, Kalantri A (1990) Electrophysiologic investigation of thallium poisoning. Muscle Nerve 13(5):433-437

10. McMillan TM, Jacobson RR, Gross M (1997) Neuropsychology of thallium poisoning. J Neurol Neurosurg Psychiatry 63(2):247450

11. Heyl T, Barlow RJ (1989) Thallium poisoning: a dermatological perspective. Br J Dermatol 121(6):787-791

12. Malbrain M, Lambrech G, Erik Zandijk, Demedts P, Neels H, Lamber W et al (1997) Treatment of severe treatment of severe thallium intoxication. J Toxicol Clin Toxicol 35(1):97-100

13. Papp JP, Gay PC, Dodson VN, Pollard HM (1969) Potassium chloride treatment in thallotoxicosis. Ann Intern Med 71(1):119-123

14. Flomenbaum NF, Goldfrank LR, Hoffman RS, Howland MA, Lewin NA, Nelson LS (eds) (2006) Goldfrank's toxicology emergency, 8th edn. McGraw Hill, New York, PP 1369. 